\title{
Insights from the Physics and Astronomy New Faculty Workshop: How do new physics faculty teach?
}

\author{
Stephanie V. Chasteen $\oplus^{*}$ \\ Chasteen Educational Consulting, UCB 390, Boulder, Colorado 80029, USA \\ Rajendra Chattergoon \\ School of Education, University of Colorado Boulder, UCB 390, Boulder, Colorado 80029, USA
}

(Received 13 May 2020; accepted 2 November 2020; published 28 December 2020)

\begin{abstract}
Effective faculty professional development must be participant centered; tailored to the needs and interests of the faculty who engage in it. In order to better understand those needs and interests, we investigate how knowledge, attitudes, beliefs, and teaching practice vary among new physics faculty, using surveys of a large sample $(n=442)$ of participants in the Physics and Astronomy New Faculty Workshop (NFW). The "innovation-decision model" guides our understanding of the evolution of faculty teaching practice, and "selfdetermination theory" and the "theory of planned behavior" inform our understanding of necessary preconditions for that change. We find that most new physics faculty are aware of published teaching approaches, but that this awareness has not increased compared to a decade ago [C. Henderson and M. H. Dancy, Phys. Rev. Phys. Educ. Res. 5, 020107 (2009)] and is lower than the experienced faculty in our sample. New physics faculty also value student-centered instruction, are interested in using it, and feel that there is peer support for using student-centered instruction. Some new faculty have experienced student-centered instruction as a student or teaching assistant, as well. They are not confident of their ability to enact such practices, however, showing that self-efficacy is an important target for faculty learning. New physics faculty also reported high levels of use of student-centered practice which were similar to experienced faculty in this study and similar or higher than a study from a decade ago. Overall, our results suggest a continued shift in norms in the physics community, such that most new physics faculty enter the professoriate needing minimal encouragement to try student-centered instruction, having already experienced and experimented with such techniques. We do find, however, that about $20 \%$ of new faculty are not as open to student-centered instruction and have not yet experimented with it, and that more of these faculty are at Ph.D.-granting institutions. We propose that the innovation-decision model might be best imagined as cyclical, with faculty moving forward and backwards along stages of the cycle as they experiment with their teaching. We recommend those creating professional development experiences for faculty explore opportunities to support faculty as agentic learners engaged in a process of lifelong learning by helping them develop self-efficacy, agency, and metacognition. One way to accomplish these goals might be to focus professional development on faculty choosing something new to try, and (critically) learning from the experience. We also encourage the field to move away from focusing research and professional development on specific, branded teaching practices.
\end{abstract}

DOI: 10.1103/PhysRevPhysEducRes.16.020164

\section{INTRODUCTION}

Despite a wealth of evidence for the effectiveness of student-centered teaching practices in science, technology, engineering and math (STEM) [1], a gap persists between this research and common practices of STEM faculty [2-4].

\footnotetext{
*Corresponding author. stephanie@chasteenconsulting.com

Published by the American Physical Society under the terms of the Creative Commons Attribution 4.0 International license. Further distribution of this work must maintain attribution to the author(s) and the published article's title, journal citation, and DOI.
}

Discipline-based faculty professional development is an important part of increasing student-centered teaching practices [3,5-7]. However, just as student-centered instruction provides an effective way to teach STEM content, participant-centered professional development is more likely to lead to lasting conceptual and behavioral change among faculty. Thus, professional development must be designed to meet the existing needs and interests of those it aims to serve [8-11].

\section{A. Defining student-centered instruction}

Student-centered instruction is a broad category of instructional techniques and approaches based on 


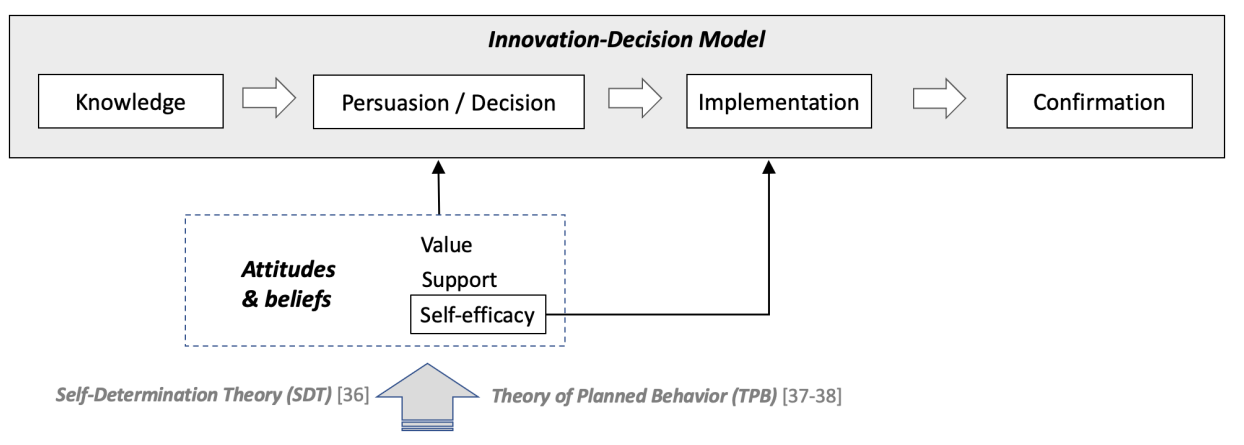

FIG. 1. The innovation-decision model [2,28]; dotted lines indicate contributing factors to the ID stages.

constructivism, or the theory that students must actively develop their own understanding based on prior knowledge through active learning and engagement [12].

In this paper, we distinguish student-centered instruction from specific classroom practices or active learning. Student-centered instruction is any instructional technique or classroom assessment based on constructivism. Active learning is a type of student-centered instruction in which students are interacting intellectually with the course material and thinking about what they are learning. Not all student-centered instruction includes active learning. Student-focused assessment refers to techniques that align with the principles of constructivism for the purpose of identifying prior understandings.

Evidence-based instructional practices (EBIPs) are a set of concrete, identifiable classroom strategies. As their name implies, EBIPs are based on well-documented principles of learning and have been shown to improve student learning outcomes; thus, they align with the general principles of student-centered instruction. EBIPs include published techniques like Peer Instruction or Just-in-Time-Teaching, as well as more general strategies like group problem solving [13]. The vast majority of EBIPs are active learning practices (like Peer Instruction), but assessments (such as concept inventories) can also be considered to be EBIPs. While EBIPs are a general category of teaching practices, physics has historically focused on EBIPs that are published and branded [13]. Our research suggests, however, that it is very limiting to focus only on such published and branded EBIPs in promoting active learning.

\section{B. The innovation-decision model for instructional decision making}

A variety of issues affect faculty members' decision to try, and persist in using, student-centered teaching practices. While outside the scope of this study, these factors include systemic issues, such as whether teaching improvement and innovation is rewarded, and whether the home department is supportive of teaching [14-18]. Additionally, characteristics of the faculty themselves, such as motivation, self-image and identity, knowledge, and teaching skill, influence their decision making [14,18-21]. To better meet the needs and interests of STEM faculty, and to help design high-quality professional development, many researchers have investigated the attitudes, interests, beliefs, and practices of faculty across STEM disciplines such as biology [14,19], chemistry [17], geology [22,23], physics [11,24], astronomy [25], and mixed disciplines [26]. Further understanding these needs and interests is key to designing participant-centered instructional development that helps support faculty members' sustained use of student-centered instruction.

Faculty members' decision to use any particular EBIP is often conceptualized as progressing through the steps of the "innovation-decision model" (ID) [19,27]. ID was first described by Rogers [27] to explain how technological innovations spread and later used by researchers across several areas. One area in which ID has been used is that of the spread of educational innovations; in such a framework, faculty proceed through multiple steps:

1. Knowledge of the innovation

2. Persuasion of the benefits of the innovation

3. Decision to adopt the innovation

4. Implementation of the innovation, and, finally,

5. Confirmation and reinforcement of that decision

This model is outlined in the top of Fig. 1; we combine the "persuasion" and "decision" stages in keeping with Andrews and Lemon [19], who found these were not distinct phases in faculty decision making.

The current study focuses on what leads to "implementation," primarily from a faculty behavior-change perspective. Faculty awareness of EBIPs has been found to be helpful, but insufficient, in generating long-term change in instruction [11,28-31]. Attitudes and beliefs are also an important element in instructors' decisions to reflect on and experiment with their teaching [32-35]. However, there is not widespread consensus on which attitudes and beliefs are most critical to support change [3] —a gap which this paper aims to help fill.

Note that the ID model is intended to apply to a specific instructional technique (EBIP), not student-centered instruction in general. While we are unaware of a research base requiring that it be limited to a specific technique, we do generally use it to refer to EBIP use in this paper. 


\section{Theoretical framework for faculty decision making}

We have found two theories to be particularly informative as a lens through which to understand faculty decision making: "self-determination theory" (SDT) [36] and "theory of planned behavior (TPB)" [37,38]. Each describes similar, complementary elements for enhancing intrinsic motivation and influencing behavior change. Studies outside of STEM education have found SDT and TPB to be complementary [39,40], and SDT has been used as a lens on instructional change [26]. However, we are not aware of other authors who have combined them in an instructional change context or applied them to the ID cycle.

Self-determination theory (SDT) indicates that there are three main influences of intrinsic motivation: "competence" (a sense of mastery), "autonomy" (having agency and a sense of integration with one's self-concept), and "relatedness" (connection to others). However, since intention does not always translate to action, we draw on the theory of planned behavior (TPB) that describes necessary conditions for such intention to lead to behavior: "attitudes" (perceived benefits and value of the behavior), "subjective norms" (social influence and opinions of others), and "perceived behavioral control" (difficulty of the behavior). Within TPB, perceived behavioral control is the lynchpin which helps translate an intention to action. Perceived behavioral control includes a belief that one has the ability to perform the behavior in question, that the behavior is not too difficult, and that the behavior is under one's own control, and is thus related to both autonomy [36] and the (perhaps more familiar concept of) self-efficacy [40,41]. This connection with self-efficacy is further supported by Bandura's assertion that self-efficacy is one component of agency [41] and findings that self-efficacy is strongly linked to intention, which can lead to concrete changes in behavior in studies of dietary health $[39,40]$. Thus, selfefficacy may be a critical factor in faculty's instructional change.

We use these frameworks to identify the attitudes and beliefs which may be important for supporting faculty instructional decision making [26,42-44]:

1. Perceived value of student-centered instruction (TPB attitudes),

2. Perceived support by others in use of studentcentered instruction (SDT relatedness; TBP subjective norms), and

3. Self-efficacy in using student-centered instruction (SDT competence and autonomy; TPB perceived behavioral control).

Our measurements probe these three areas of focus, and we posit these as being critical influences on a faculty member's movement to the persuasion or decision stage in their determination of whether to use student-centered instruction, with self-efficacy as being particularly critical to translate that intention to implementation. To this end, this paper provides information about the knowledge, motivation, and self-reported use of student-centered teaching practices of a large sample of new physics faculty.

\section{The New Faculty Workshop}

We report on a large sample $(n=442)$ of participants in the Physics and Astronomy New Faculty Workshop, starting in 2015. The NFW is a multiday professional development workshop initiated in 1996 that engages a significant fraction (40\%) of new physics faculty members in the U.S. The mission of the NFW is to improve student learning by helping all faculty become knowledgeable users of student-centered instruction, with a historic emphasis on branded and recognizable EBIPs. The NFW has been demonstrated to have positive impacts on physics faculty knowledge and motivation to use EBIPs, but not on long-term sustained use [29,30]. However, much of the information that we have about physics faculty EBIP use is from an oft-cited series of survey studies by Henderson and Dancy published a decade ago $[29,31]$. These studies were based on a national survey of physics faculty that asked about knowledge and use of active learning strategies, including a set of 24 EBIPs based on physics education research (PER). They found that many faculty were already dissatisfied with lecture-based teaching, that faculty were interested and motivated to try active learning (including EBIPs) that many had used them, and that faculty felt hindered by lack of knowledge of and time to learn to use these strategies [28]. Among faculty who did make use of EBIPs, they often modified them in potentially unproductive ways [28,29,31], and a third of physics faculty discontinued the use of any strategy [30]. This work has been informative for STEM faculty development in other disciplines [19,22] and the current study aims to build on our understanding with more recent data.

\section{E. Research questions}

The research questions guiding our study were

1. To what degree do new physics faculty members possess attitudes and beliefs-particularly selfefficacy, value, and perception of support by others-which could support decisions to use student-centered teaching practices? (persuasion or decision stage of ID model)

2. To what degree do new faculty report knowing about student-centered instruction (particularly EBIPs), and how has this changed over the past decade? (knowledge stage of ID model)

3. To what degree do new faculty report using studentcentered teaching practices, and how has this changed over the last decade? (decision and implementation)

4. How do teaching practices change one year after a professional development experience? (implementation and confirmation stages of ID model) 
We use these findings to explore the implications for the design of professional development. Our focus is on new faculty members who are within their first five years of a teaching appointment, although we include relevant comparisons to a small group of experienced faculty. We do not report on the design or effects of the NFW itself, although we examine responses at one year after the workshop to provide insight about how faculty take up teaching practices.

\section{METHODS}

\section{A. Research design}

The current study is a quantitative study focused on teaching attitudes, beliefs, and practices of new physics faculty as established via self-report surveys preworkshop, immediately postworkshop, and one-year postworkshop. Surveys were chosen as the data collection tool to allow for large sample size, enabling the efficient collection of a breadth of information. In addition to data from new faculty, we also collected data from a small sample of experienced faculty (EFW respondents) and a subset of faculty that responded to a one-year follow-up survey. We use these data to contextualize the new faculty responses.

Because the original aim of data collection was workshop evaluation (not generalizable research), we focused on survey questions which served an evaluative purpose; which could formatively inform workshop design, or summatively evaluate the intended outcomes. In some cases, instruments validated to measure the SDT or TPB constructs were not available or they would have greatly increased the length of the survey, increasing survey fatigue and reducing response rates.

\section{B. Study population}

The NFW is organized by several professional societies: the American Association of Physics Teachers (AAPT), the American Physical Society (APS), and the American Astronomical Society (AAS). It is offered twice a year, typically in June and November, to a cohort of approximately $50-70$ faculty; this comprises about $40 \%$ of the 340 physics faculty hired each year in the U.S. [45] and represents an increase from 25\% prior to 2007 [46]. Attendees are physics (85\%) and astronomy (15\%) faculty, in a distribution similar to national disciplinary representation [45]. Faculty must be nominated by their chair to attend (though attendance is rarely required). In recent years, a oneyear faculty online learning community (FOLC) has been offered to a portion of participants postworkshop [47].

The analyses in this section include data for all 487 unique individuals that responded to one or both of the NFW pre- or postworkshop surveys. Respondents had been teaching for one or two years $($ mean $=2.5$, median $=2$, mode $=1$, $\mathrm{SD}=2.4)$. The vast majority $(94 \%)$ had been teaching for fewer than five years, with most having at least one year of teaching experience. About 1/3 of respondents (29\%) identified as female (see Table I), similar to national
TABLE I. Demographics of the NFW survey respondents.

\begin{tabular}{|c|c|}
\hline Demographic variable & Percent \\
\hline $\begin{array}{l}\text { Gender } \\
\text { Male } \\
\text { Female } \\
\text { No answer }(n=43)\end{array}$ & $\begin{array}{l}70 \\
30\end{array}$ \\
\hline $\begin{array}{l}\text { Institution type } \\
\text { Primarily undergraduate } \\
\text { Ph.D. granting } \\
\text { Master's granting } \\
\text { Other } \\
\text { No answer }(n=158)\end{array}$ & $\begin{array}{r}53 \\
40 \\
5 \\
2\end{array}$ \\
\hline $\begin{array}{l}\text { Race or ethnicity } \\
\text { White } \\
\text { Asian } \\
\text { Hispanic } \\
\text { Black } \\
\text { Two or more races } \\
\text { American Indian } \\
\text { No answer }(n=61)\end{array}$ & $\begin{array}{r}67 \\
23 \\
4 \\
2 \\
2 \\
1\end{array}$ \\
\hline $\begin{array}{l}\text { Undergraduate degree location } \\
\text { North America } \\
\text { Asia } \\
\text { Europe } \\
\text { Other } \\
\text { No answer }(n=39)\end{array}$ & $\begin{array}{r}64 \\
19 \\
12 \\
5\end{array}$ \\
\hline Total & 487 \\
\hline
\end{tabular}

Those with no answer are excluded from the total used to calculate the percent in any category.

representation [48]. The majority (67\%) identified as White, but a sizable fraction (23\%) identified as Asian, which exceeds the national representation in physics (14\%) [49]. Reported institution type was nearly evenly split between primarily undergraduate institutions (53\%) and Ph.D.-granting institutions (40\%), with the remaining identifying as master's granting or other. This sample is an underrepresentation of Ph.D.-granting institutions compared to national statistics of all physics faculty, given that nearly twice as many physics faculty are employed in departments granting a Ph.D. [50]. Thus, the NFW survey respondents were generally representative of new physics and astronomy hires but with an overrepresentation of those identifying as Asian and those from primarily undergraduate institutions.

A subsample of respondents completed a survey one year after the NFW. The one-year sample was generally representative of the NFW sample: $32 \%$ female, $69 \%$ White, $3.6 \mathrm{yr}$ of teaching experience $(\sim 1$ additional year compared to the general NFW sample), though they were twice as likely to have participated in the FOLC (17\% of presurvey respondents and $26 \%$ of one-year survey respondents participated in the FOLC).

Additionally, in March 2016 an Experienced Faculty Workshop (EFW) was offered. The EFW survey 
respondents were 40 midcareer faculty with a greater number of years of teaching experience $($ mean $=17.8$, median $=16$, mode $=12, \mathrm{SD}=8.8$ ) and similar demographics to the NFW. EFW participants had not typically attended a NFW.

\section{Survey instruments}

Our survey instruments measured different elements of instruction (student-centered instruction, active learning, and EBIP use; see Sec. I for a definition of terms).

\section{Survey administration}

The surveys took between 10 and 20 min to complete. All surveys included demographic questions and questions about teaching attitudes and practices. The postworkshop survey also included workshop evaluation questions. Copies of the survey instruments are provided in the Supplemental Material [51]. Below, the main question blocks are described further.

\section{Attitudes and beliefs about active learning}

A series of seven Likert-scale questions assessed participants' attitudes and beliefs about active learning: self-efficacy, value, and perception of support by others (see Sec. I and Fig. 1). These questions were asked preworkshop, postworkshop, and at one year. For some cohorts, we included a retrospective pretest on the postworkshop survey, where participants were asked to estimate their preworkshop attitudes [43,52].

For these seven questions, respondents were first presented with a broad definition of active learning as "a model of instruction in which students are actively doing things, and thinking about what they are learning, rather than watching or listening. Active learning may apply to small or large classes." First, respondents were asked to rate their level of knowledge (item 1) and skill (item 2) in using active learning using a 4-point scale $(1=$ none, $2=$ a little, $3=$ some, $4=\mathrm{a}$ lot). Then, they rated how effective they believed active learning strategies were (item 3), how motivated they felt to incorporate active learning (item 4), how supported by others they felt in incorporating active learning (item 5), and how confident they felt that they could support a colleague (item 6) and get good student evaluations (item 7) while incorporating active learning using a modified scale $(1=$ not very, $2=$ a little bit, $3=$ moderately, $4=$ highly). Throughout the rest of the paper, we denote the results of these questions by item number for clarity. We categorize these (ad hoc) as measuring the three areas of attitudes and beliefs identified in section IC: value of active learning (items 3, 4), selfefficacy (items 1, 2, 6, 7), and perception of support by others (item 5).

The structure of the questions was inspired by a similar set of questions from mathematics inquiry workshops [53].
We chose not to use or adapt a preexisting instrument validated to measure attitudes and beliefs because such an instrument would only be able to address one or two areas of interest, and would greatly increase survey length, thus not serving the aim of the workshop evaluation. For example, the Self-Efficacy Towards Teaching Inventory [54] was considered based on its use in other professional development contexts [55], but we decided against its use due to its length and narrow scope. Although this decision limits the validity of our surveys to measure the SDT and TPB constructs, we are able to observe coarse differences along the response scale in response to participation in the workshop, which was the goal of the evaluation.

\section{Self-reported use of student-centered instruction}

To measure self-reported teaching practice, we used instruments which measured different elements of instruction: student-centered instruction (as measured by a validated instrument), time spent on active learning, and use of specific EBIPs (next section).

Student-centered instruction: We used the PostSecondary Instructional Practices Survey (PIPS), developed by Walter and colleagues [56] to measure self-reported use of student-centered instruction. The PIPS consists of a series of 24 statements about instructional practice (e.g., "I structure class so that students regularly talk with one another about course concepts"), rated on a 5-point scale $(0=$ not at all, $1=$ minimally, $2=$ somewhat, $3=$ mostly, or $4=$ very descriptive of my teaching). On the June 2015 presurvey, PIPS item 20 was not given to respondents due to an error in the survey administration. These questions were asked preworkshop and at one year. The developers of the PIPS instrument provide validity evidence using factor analysis to support their scoring recommendations (student-centered and instructor-centered factors).

Because the PIPS is a relatively new instrument, we conducted independent analyses of the reliability and validity of the instrument using our data. We find that the overall PIPS score (all 24 items) and the studentcentered factor score (13 items) demonstrate good reliability, with Cronbach's alpha values of 0.83 and 0.88 , respectively, on the preworkshop survey and 0.77 and 0.82 at one year. However, the instructor-centered factor $(8$ items) had low reliability, with Cronbach's alpha of 0.50 and 0.49 for the preworkshop survey and one-year administration, respectively, indicating measurement error in scores for this factor. We find good variability in item difficulty (the percent of respondents answering favorably; $p$ values) of PIPS items. However, the point-biserial correlations (correlating an item score with the total score) indicated that there were several problematic items with very low correlations $(<0.2)$, mostly related to the instructor-centered construct. Furthermore, an exploratory factor analysis conducted by the authors supported a single-factor solution for the PIPS. Thus, we conclude that most of the 
items on the instructor-centered factor are problematic and that (at least for our sample) the PIPS should be scored using only one factor: the student-centered items, plus one additional instructor-centered item which was also relevant to this factor (item 17: "I provide time for students to reflect about the processes they use to solve problems"). Thus, we use a modified version of the PIPS as a measure of studentcentered practice. In this paper, we report results for this modified student-centered PIPS score (the original studentcentered factor, plus item 17). On this modified PIPS, a high score indicates a high level of use of student-centered instructional practices.

Active learning: To collect information about active learning use, we asked, "In the 'lecture' portion of your course, please estimate the percentage of class time spent on active-learning strategies (e.g., student activities, questions, and discussion)." This question has also been used in several recent studies in the geosciences [22,23]. Similar to those studies, we grouped responses across cohorts into the following categories: high ( $>25 \%$ of class time spent on active learning), medium (11\%-25\% of class time spent on active learning), low (1\%-10\% of class time spent on active learning), none ( $0 \%$ of class time spent on active learning). This item was not asked in one particular instance of the preworkshop survey (June 2015).

\section{Knowledge and use of evidence-based instructional practices}

One aim of this paper is to provide current data for comparison to the historical 2007 survey of physics faculty on knowledge and use of EBIPs [28,30,31]. A series of questions asked about respondents' familiarity with and use of 12 physics and astronomy teaching methods aimed to support student-centered instruction, such as Peer Instruction [57] and Interactive Lecture Demonstrations [58]. EBIPS were almost all "branded," as per definitions from Khatri et al. [13]; the full list of EBIPs we surveyed can be seen in Fig. 4. EBIPS were chosen to match Henderson and Dancy [28], but we removed some of the teaching approaches in the original study (such as Video Laboratory), as they are no longer a strong focus in the physics community, and added the PhET Simulations [59] and concept inventories [60]. "Concept inventories" is the only EBIP on the list which is unbranded, and is an assessment strategy, rather than an active learning strategy.

Response options were exclusive (i.e., respondents could choose only one), and we used the 5-point response scale provided by Henderson and Dancy [28]; $0=\mathrm{I}$ have never heard of it/ not sure, $1=$ I've heard the name but do not know much else about it, 2 = I am familiar with it but have never used it, $3=$ I have used all or part of it in the past, and $4=$ currently use all or part of it. Because of changes in the surveys, we recoded response options from June and November 2015 so that they matched the survey response options in subsequent cohorts. For example, "I have heard of this technique" was recoded to "I've heard the name but do not know much else about it," and "I have used it in the past" was recoded to "I have used all or part of it in the past." These questions were also asked on the one-year survey, but the answer choices were simplified to focus on use (I have never used it, have used all or part of it in the past, I currently use all or part of it). The "I have never used it" option was later added as an option for some cohorts once we realized it was needed for completeness.

When analyzing responses, we coded a participant as being "familiar" with the method if they reported either familiarity or use of the method: "I am familiar with it but have never used it," "I have used all or part of it in the past," or "I currently use all or part of it." We coded a participant as having "tried" a teaching method if they chose "I currently use all or part of it" or "I have used all or part of it in the past."

The earlier study included a mixed sample of physics faculty with an average of 15.4 years of teaching experience, whereas this study sample is primarily new faculty with an average of 2.5 years of teaching experience. This difference in study populations restricts our ability to make direct comparisons between the two studies. An updated study by these authors, using a national sample, is in progress [61].

It is possible that interactive teaching has become more normative over the past ten years, and thus that new faculty have experienced EBIPs as students or teaching assistants prior to their professional appointment. This experience could influence their later use of such techniques. To test this idea, we added options for respondents to indicate whether they had used the technique as a teaching assistant (TA) or student for two cohorts (June 2015 and June 2019). Response options for the TA and student items were not exclusive.

\section{RESULTS}

\section{A. Response rates}

We have a total of 482 responses preworkshop, 417 postworkshop, and 370 matched pre- or postworkshop responses (Table II). Within this paper we indicate where matched (pre or post) data are presented, but as we are typically not reporting growth after the workshop, we do not typically restrict the dataset to this matched sample but report the full preworkshop or postworkshop responses as appropriate. Response rates were relatively high $(85 \%$ average) for the preworkshop survey but lower for subsequent surveys (73\% postsurvey average; $32 \%$ one-year average). Sample sizes for specific analyses may be lower as not all individuals answered all questions. A total of 128 respondents completed a survey one year after the NFW (see Table II). The response rate for the experienced faculty workshop was $87 \%$ preworkshop.

\section{B. Attitudes and beliefs about active learning}

This section addresses research question 1, regarding the three attitudes and beliefs hypothesized to be important for 
TABLE II. Sample sizes for workshop surveys.

\begin{tabular}{|c|c|c|c|c|c|}
\hline \multirow[b]{2}{*}{ Cohort } & \multirow[b]{2}{*}{ Workshop registration } & \multicolumn{4}{|c|}{ Sample sizes (Survey response rate \%) } \\
\hline & & Preworkshop & Postworkshop & matched Pre/Post & One year \\
\hline June 2015 & 71 & $63(89)$ & $56(79)$ & $50(70)$ & $32(45)$ \\
\hline November 2015 & 78 & $64(82)$ & $61(78)$ & $45(58)$ & $31(40)$ \\
\hline June 2016 & 54 & $47(87)$ & $45(83)$ & $40(74)$ & $24(44)$ \\
\hline November 2016 & 68 & $57(84)$ & $49(72)$ & $44(65)$ & $21(31)$ \\
\hline June 2017 & 66 & $58(88)$ & $51(77)$ & $46(70)$ & $13(20)$ \\
\hline November 2017 & 72 & $60(83)$ & $45(63)$ & $42(58)$ & $7(10)$ \\
\hline June 2018 & 60 & $48(80)$ & $41(68)$ & $38(63)$ & $\ldots$ \\
\hline October 2018 & 54 & $45(83)$ & $36(67)$ & $34(63)$ & $\cdots$ \\
\hline March 2016 EFW* & 46 & $40(87)$ & $33(72)$ & $31(67)$ & $\cdots$ \\
\hline Totals & 569 & $482(85)$ & $417(73)$ & $370(65)$ & $128(32)$ \\
\hline
\end{tabular}

"EFW is the comparison group from the Experienced Faculty Workshop.

behavior change (self-efficacy, value, and support by others) which could support student-centered practice. For these types of questions, we find the medians to be particularly informative because actual responses cannot fall between two response categories.

Before the workshop, respondents' beliefs in the effectiveness of and motivation to use active learning were near the top of the scale (items 3 and 4; means: 3.6 and 3.7, medians: 4; matched pre- and postsample); see Table III. These items are related to participants value of active learning. Feeling supported by others (item 5; mean 3.4, median 4) is also fairly high. The lowest rated items were the knowledge of active learning (item 1), skill in using active learning (item 2), and their ability to support a colleague in their use of active learning (item 6), and ability to get good student evaluations while using active learning (item 7). These all relate to participants self-efficacy in using active learning. For the four lowest-rated items, the median was 3 or below, with the median for skill at 2 . This suggests that knowledge, skill, and confidence (in teaching colleagues or in student evaluations) all show room for growth, and that these may be productive areas for professional development.
Gains from preworkshop to postworkshop were computed by subtracting postworkshop responses from preworkshop responses. The effect size (mean gain divided by the pooled standard deviation) provides an estimate of the practical significance of these gains. An effect size of "1" or greater indicates that participants would select, on average, a response one category higher on the survey scale after participating in the workshop (e.g., select "none" preworkshop and "a little" postworkshop). The only area showing appreciable gain postworkshop was knowledge of active learning (item 1), based on the effect size. This result suggests that skill (item 2) and confidence (items 6 and 7) could benefit from more focus. For a matched sample of one-year respondents (not shown), we find no clear gains on any of these items. In a separate study, however, we find indication that participants may have a renewed sense of motivation and interest in active learning postworkshop that is not reflected in these results [43]: knowledge (item 1), skill (item 2), motivation (item 4), and supporting a colleague (item 6) all demonstrated retrospective gains when respondents were asked (postworkshop) to rate both their pre- and postworkshop attitudes. These results

TABLE III. Mean, median, and gain scores for attitude and belief questions.

\begin{tabular}{|c|c|c|c|c|c|c|c|c|}
\hline \multirow[b]{2}{*}{ Questions $^{*}$} & \multirow[b]{2}{*}{$\mathrm{n}$} & \multicolumn{2}{|c|}{ Preworkshop survey } & \multicolumn{2}{|c|}{ Postworkshop survey } & \multicolumn{2}{|c|}{ Gain $^{* *}$} & \multirow[b]{2}{*}{ Effect size $^{\dagger}$} \\
\hline & & Mean (SD) & Median & Mean (SD) & Median & Mean (SD) & Median & \\
\hline 1. Knowledge & 333 & $2.8(0.7)$ & 3 & $3.4(0.7)$ & 3 & $0.7(0.9)$ & 1 & 0.9 \\
\hline 2. Skill & 333 & $2.3(0.7)$ & 2 & $2.7(0.7)$ & 3 & $0.4(0.8)$ & 0 & 0.5 \\
\hline 3. Effectiveness & 313 & $3.7(0.6)$ & 4 & $3.8(0.4)$ & 4 & $0.2(0.6)$ & 0 & 0.3 \\
\hline 4. Motivation & 288 & $3.6(0.7)$ & 4 & $3.8(0.4)$ & 4 & $0.2(0.7)$ & 0 & 0.4 \\
\hline 5. Supported by Others & 272 & $3.4(0.7)$ & 4 & $3.4(0.7)$ & 3 & $0.0(0.8)$ & 0 & 0.0 \\
\hline 6. Supporting Colleague & 277 & $2.9(1.0)$ & 3 & $3.2(0.8)$ & 3 & $0.3(1.0)$ & 0 & 0.3 \\
\hline 7. Evaluations & 214 & $3.1(0.8)$ & 3 & $3.1(0.8)$ & 3 & $0.0(0.9)$ & 0 & 0.1 \\
\hline
\end{tabular}

"Scales: $1=$ none, $2=$ a little, $3=$ some, $4=$ a lot $1=$ not very, $2=$ a little bit, $3=$ moderately (questions 1 and 2 ), and $1=$ not very, $2 \underset{* *}{=}$ a little bit, $3=$ moderately, $4=$ highly (questions $3-7$ ).

** Gain scores are computed by subtracting postworkshop survey responses from preworkshop survey responses. The mean gain is the average of the individual gain scores for each item. The median gain is the median of individual gain scores.

The effect size is computed by dividing the mean gain by the pooled standard deviation across all pre- and postsurvey responses. 
tentatively suggest that participants' understanding of active learning itself (including the challenges it entails) may be affected by the workshop, resulting in a downgrading of their overly optimistic preworkshop ratings.

We do observe somewhat different outcomes for those at Ph.D.-granting institutions, with slightly greater gains in their belief in the effectiveness of active learning compared to those at non-Ph.D.-granting institutions (item 3; effect sizes 0.6 and 0.2 , respectively) and lower confidence they could get good student evaluations while using active learning strategies (item 7; effect sizes -0.3 and 0.3 , respectively).

\section{Time spent on active learning}

This section will explore the degree of use of studentcentered teaching practices (RQ3), based on measures of use of active learning, student-centered practice, and EBIPs.

Most NFW and EFW respondents (45\%) report "high" use of active learning (more than $25 \%$ of class time spent on active learning), and $22 \%$ report low levels of use of active learning; see Fig. 2, left side. To investigate changes in use of active learning, we compared matched preworkshop and one-year responses ( $n=75$ matched responses). The fraction of these faculty using high levels of active learning increases from $41 \%$ (preworkshop) to $67 \%$ (one year), with very few reporting low levels of use at one year; see Fig. 2, right side. Upon examining individual changes in the use of active learning for these respondents, we find that $51 \%$ maintain the same level of active learning use at one year, $41 \%$ increase their level of active learning, and only $8 \%$ decrease their level of use of active learning. Typically, high users of active learning remain high users, and medium users increase their use. The levels of use of active learning for one-year respondents exceed that of the experienced faculty-67\% of one-year respondents report using high levels of active learning, compared to $45 \%$ of the experienced sample.

We examined available data for evidence of concurrent validity (whether other measures of the construct give the same results) and found consistency between time spent on active learning and other measures of teaching practice. There is a correspondence between time spent on active learning and reported use of active learning methods (EBIPs); about $93 \%$ of participants who report high levels of active learning have used at least one EBIP (compared to $72 \%$ of those with low levels of active learning use.) Moreover, respondents with greater reported time spent on active learning also have higher student-centered PIPS scores, on average: the mean student-centered PIPS score is 53.2 (SD 13.2) for those with low levels of time spent on active learning, but 69.5 (SD 12.2) for those with high levels of time spent on active learning. The consistency of these other measures of teaching practice with self-reported time spent using active learning provides some reassurance as to the validity of the (latter) measurement.

\section{Use of student-centered teaching practice (PIPS survey)}

For the NFW sample $(n=404)$, the modified studentcentered PIPS score is spread across possible values in a bell-shaped curve (mean 62.1, SD 14.0); $22 \%$ of the sample have scores on the low end (PIPS score $<50$ ) and $28 \%$ have scores on the high end (PIPS score $>70$ ). These values are consistent across cohorts, with no significant variations. The student-centered PIPS score is slightly lower for those at Ph.D.-granting institutions (mean 60.5, SD 15.7) than at non-Ph.D.-granting institutions (mean 64.0, SD 13.0). For the 40 EFW respondents, the student-centered PIPS score is 61.2 (SD 15.5). These PIPS values for EFW and

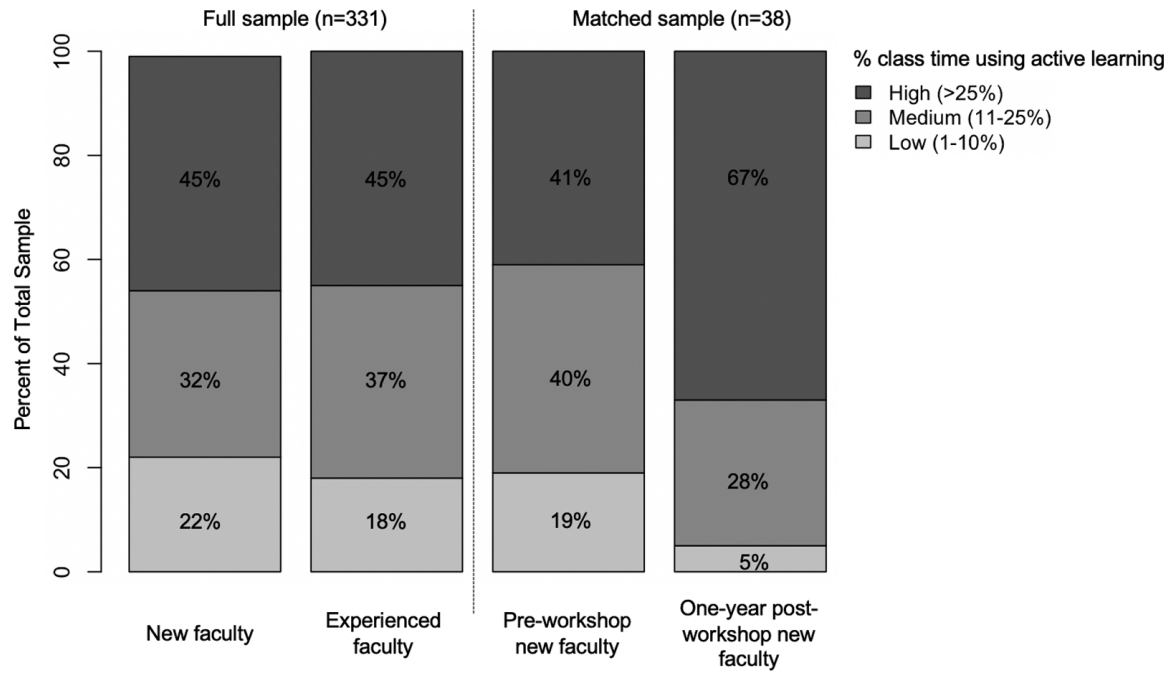

FIG. 2. Percent of class time spent active learning, as reported by survey respondents. On the left side, "new faculty" are all respondents to the NFW preworkshop survey $(n=331)$, "experienced faculty" are respondents to the EFW preworkshop survey $(n=38)$. On the right side are the matched preworkshop-one-year sample of NFW respondents $(n=75)$. 
NFW respondents are similar to one another and are higher than those reported for the original PIPS study [56] which reported scores of 55 (STEM courses) and 65 (non-STEM courses) for the nonmodified student-centered PIPS scores. We find a moderate correlation $(\mathrm{r}=0.42)$ between new faculty members' reported skill (item 2) in using active learning and the PIPS score, which suggests that participants' self-reported ratings on the "skill" item are associated with student-centered teaching practices.

In the one-year sample, we observe higher student-centered PIPS scores (mean 69.6, SD 10.9; $n=120$, unmatched sample); higher than any values originally reported [56]. The matched pre or one-year sample reports a $10 \%$ gain in the student-centered PIPS (effect size 0.8), and only $6 \%$ use low levels of student-centered practice (score $<50$ ).

\section{E. Knowledge and use of evidence-based instructional practices}

Below, we will first explore the degree of knowledge of EBIPs (RQ2) and then the degree of use of these practices (RQ3).

\section{Familiarity with $E B I P$, and the relationship to teaching experience}

Most respondents are familiar with at least one listed EBIP: only $18 \%$ of NFW respondents report knowing none of the listed EBIPs. They report familiarity with a median of 3 EBIPs (though this drops to 2 EBIPs for those with less than two years of teaching experience.) A small fraction $(15 \%)$ reported familiarity with more than 5 EBIPs. Respondents were most familiar with Cooperative Group Problem Solving [62], Peer Instruction, concept inventories, PhET Simulations and Interactive Lecture Demonstrations, but the percent of those who have used the method varies; Fig. 3 shows these results, sorted by level of familiarity.

Results did not vary remarkably across the 8 workshop cohorts, with consistent EBIPs typically reported as the highest (or lowest) ranked methods by each cohort. Results did vary by teaching experience. The more teaching experience new faculty have, the more they report familiarity with EBIPs. Across all EBIPs, $47 \%$ of prefaculty (student or TA), $80 \%$ of new faculty, and $92 \%$ of experienced faculty, report knowing at least one of these methods; see Fig. 4.

Faculty reported relatively low levels of exposure to any technique as a student or TA, with $10 \%$ or fewer respondents reporting experiencing the technique in that period. When aggregating across all listed EBIPs, however, we find that approximately one-third of respondents experienced at least one of these methods as a student or TA (Table IV; 2015 and June 2019 results). In general, the level of experience with EBIPs as a TA is larger for the later sample (June 2019), but the same is not true for experience with EBIPs as a student.

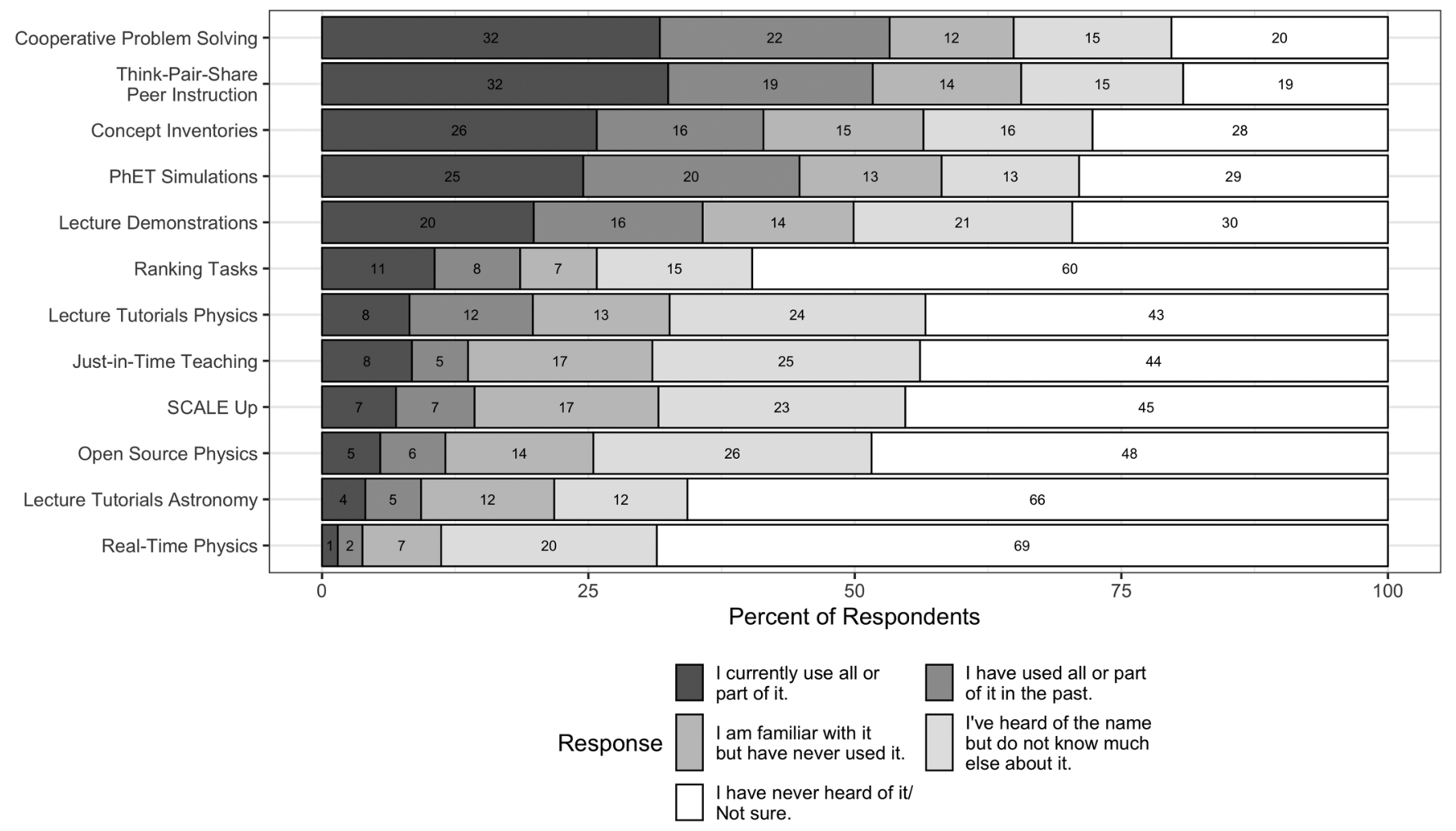

FIG. 3. Level of knowledge and use of specific EBIPs in the NFW. 


\section{Cooperative Group Problem Solving}

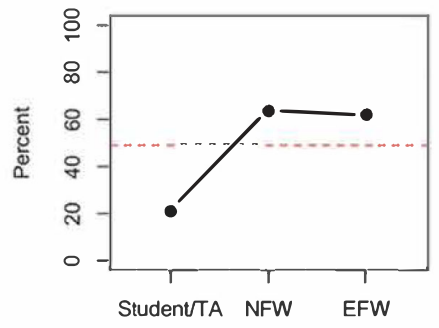

Concept Inventories

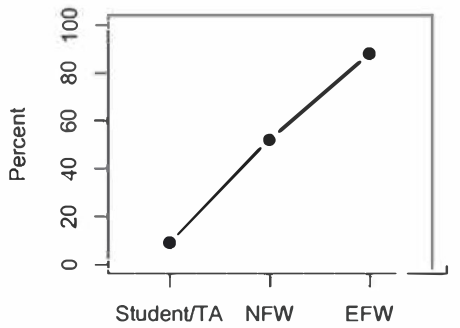

SCALE-Up and Studio

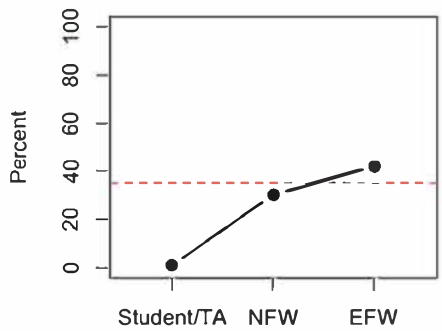

Ranking Tasks

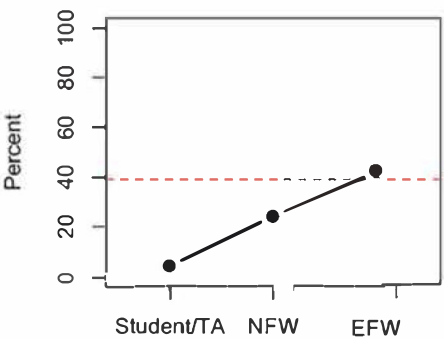

Peer Instruction

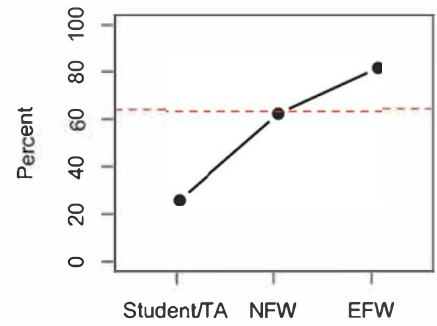

Interactive Lecture Demonstrations

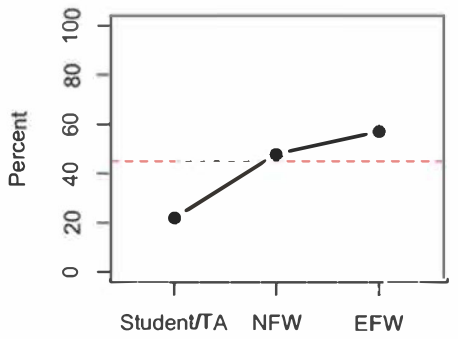

Just-in-Time-Teaching

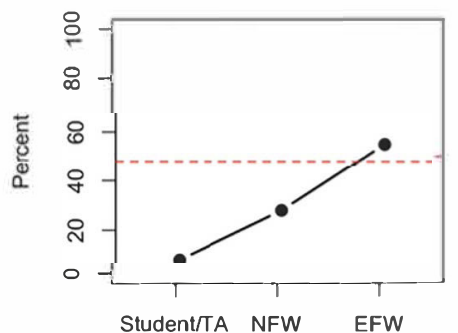

Lecture Tutorials in Astronomy

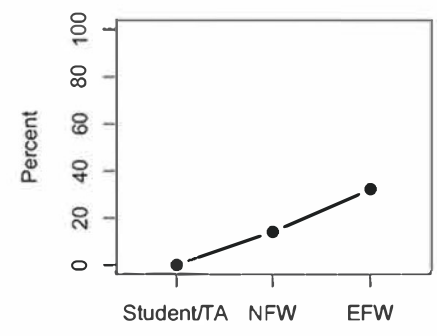

PhEI Interactive Simulations

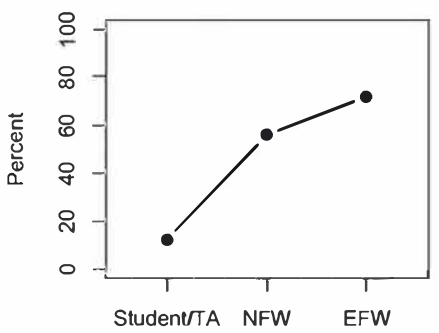

Tutorials in Introductory Physics

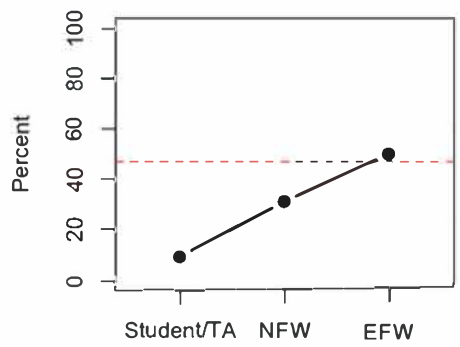

Open Source Physics

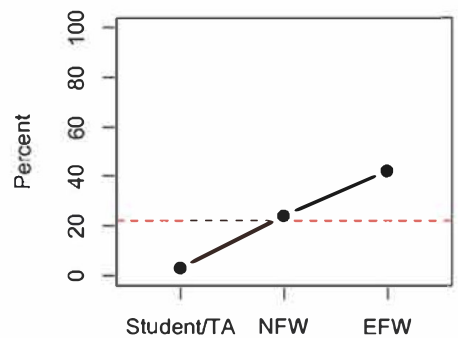

Real-Time Physics

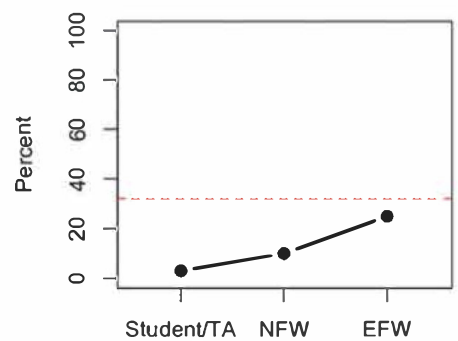

Knowledge of Any EBIP

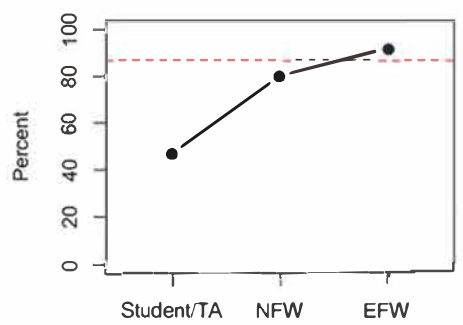

Median Number of EBIPs

Known

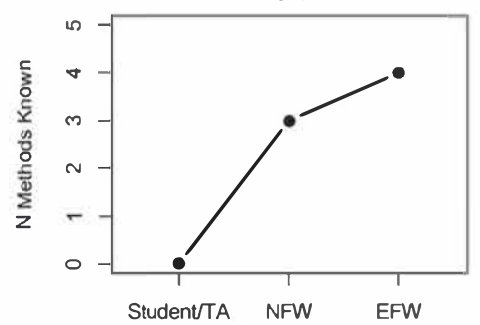

FIG. 4. Level of familiarity with specific EBIPs by teaching experience. "Familiarity" includes respondents who answered selected any of the following choices: I am familiar with it but have never used it, I have used all or part of it in the past, or I currently use all or part of it. Respondents are shown in order of increasing teaching experience: (1) Student or TA $(n=116), 0$ average years of teaching experience, data from June 2015 and June 2018 NFW cohorts; (2) New faculty ( $n=442), 2.5$ average years of teaching experience, data from NFW presurvey; (3) Experienced faculty $(n=40), 18$ average years of teaching experience, data from EFW presurvey. The dotted line shows the comparison to historical data $(\mathrm{N}=722), 15.4$ average years of teaching experience (Henderson and Dancy [1]; Tables VI and VIII). 
TABLE IV. Experience with evidence-based instructional practices as a TA or student.

\begin{tabular}{lcc}
\hline \hline & \multicolumn{2}{c}{ Percent } \\
\cline { 2 - 3 } Experience with EBIPs & June & June \\
\hline Experienced at least one EBIP as a student & 3015 & 2019 \\
Experienced at least one EBIP as a graduate TA & 16 & 34 \\
Experienced at least two EBIP as a student & 17 & 21 \\
Experienced at least two EBIP as a graduate TA & 6 & 28 \\
Sample size & 63 & 53 \\
\hline \hline
\end{tabular}

New faculty members' level of knowledge of these EBIPs is not typically higher than reported in the mixed-experience sample in the original study [28]. For any single method, the historic level of knowledge typically exceeds or meets the level of knowledge of new faculty at the NFW.

\section{Use of EBIPs, and the relationship to teaching experience}

As one measure of teaching practice, we compare the reported use of these EBIPs for the different cohorts in the study. The 5 most commonly used EBIPs were the same ones that respondents had reported the highest levels of knowledge about (see previous section), as one would expect (Table V, column B). The percent of faculty who use these methods is somewhat similar between new and experienced faculty (Table V, columns B and C) though with a few exceptions: a greater fraction of new faculty reported using Cooperative Group Problem Solving and Peer Instruction and a greater fraction of experienced faculty reported using PhET Interactive Simulations.

When aggregating across all EBIPs ("overall" data in Table V), we find that most new (57\%) and experienced faculty $(70 \%)$ used at least one EBIP, and $43 \%$ of new faculty used at least two. The average number of EBIPs used was 1.7 for new faculty; quite similar to the 1.6

TABLE V. Current use of evidence-based instructional practices (EBIPs), by teaching experience, compared to historical data. See headers for relevant comparison groups.

\begin{tabular}{|c|c|c|c|c|c|}
\hline \multirow[b]{3}{*}{ Description } & \multirow[b]{2}{*}{ A } & \multicolumn{2}{|c|}{$\begin{array}{l}\text { Full PreWorkshop data } \\
\text { (NFW vs. EFW) }\end{array}$} & \multicolumn{2}{|c|}{$\begin{array}{l}\text { Matched PreWorkshop vs. } \\
\text { One-Year sample (NFW) }\end{array}$} \\
\hline & & B & $\mathrm{C}$ & $\mathrm{D}$ & $\mathrm{E}$ \\
\hline & $\begin{array}{c}\text { Historic } \\
\text { mixed } \\
\text { sample }^{1}\end{array}$ & $\begin{array}{c}\text { NFW } \\
\text { preworkshop } \\
\text { all }^{2}\end{array}$ & $\begin{array}{c}\text { EFW } \\
\text { preworkshop } \\
\text { all }^{3}\end{array}$ & $\begin{array}{c}\text { NFW } \\
\text { preworkshop } \\
\text { matched }^{4}\end{array}$ & $\begin{array}{c}\text { NFW } \\
\text { one-year } \\
\text { matched }^{4}\end{array}$ \\
\hline $\begin{array}{l}\text { Evidence-based instructional practice (EBIP) } \\
\text { (E) }\end{array}$ & \multicolumn{5}{|c|}{ Percent of respondents currently using ${ }^{5}$ the method } \\
\hline Cooperative Group Problem Solving & 14 & 32 & 18 & 39 & 47 \\
\hline Peer Instruction & 29 & 33 & 25 & 44 & 80 \\
\hline Concept Inventories & .. & 24 & 25 & 31 & 55 \\
\hline PhET Interactive Simulations & $\ldots$ & 25 & 32 & 36 & 45 \\
\hline Interactive Lecture Demonstrations & 14 & 20 & 15 & 24 & 31 \\
\hline Tutorials in Introductory Physics & 8 & 9 & 2 & 8 & 15 \\
\hline Just-in-Time-Teaching & 8 & 7 & 10 & 5 & 7 \\
\hline SCALE-Up & 3 & 8 & 10 & 8 & 36 \\
\hline Ranking tasks & 15 & 5 & 5 & 6 & 8 \\
\hline Open source physics & 2 & 10 & 10 & 14 & 24 \\
\hline Lecture Tutorials in Astronomy & $\cdots$ & 3 & 5 & 2 & 3 \\
\hline Real-Time Physics & 7 & 2 & 0 & 0 & 3 \\
\hline \multicolumn{6}{|l|}{ Overall } \\
\hline Do not currently use any EBIP & 52 & 43 & 30 & 31 & 13 \\
\hline Use at least one EBIP & 48 & 57 & 70 & 69 & 87 \\
\hline Use at least two EBIPs & 34 & 43 & 40 & 58 & 79 \\
\hline Average number of EBIPs used & & 1.7 & 1.6 & 2.1 & 3.4 \\
\hline Average years teaching experience & 15.4 & 2.5 & 17.8 & 2.5 & 3.6 \\
\hline Sample size & 722 & 442 & 40 & 118 & 118 \\
\hline
\end{tabular}

${ }^{1}$ Historic mixed data is from Henderson and Dancy [28], Tables VI and VII. Sample is mixed faculty from two-year and four-year colleges based on a 2007 survey.

${ }^{2}$ New Faculty Workshop data is taken from preworkshop surveys in the current paper. The reported n represents the total number in the sample.

${ }^{3}$ Experienced Faculty Workshop is data from preworkshop surveys of the EFW offered in 2016.

${ }_{5}^{4}$ NFW one-year (new faculty at one year) data are taken from one-year surveys in the current paper, matched to presurvey responses.

"Use" is defined as responding positively to "I currently use all or part of it." 
reported by experienced faculty. The percent of new faculty reporting no use of any EBIPs (43\%) was greater than for experienced faculty (30\%).

Thus, despite new faculty's lower levels of familiarity with EBIPs compared to more experienced faculty, their actual use of these EBIPs is remarkably similar to that of the more experienced faculty in our study. The cohort of experienced faculty in our study spent an amount of class time on active learning similar to that of new faculty, reported similar levels of student-centered practice on the PIPS, and used similar numbers of EBIPs.

We also investigated the use of EBIPs by institution type. Because of the sample sizes of the subgroups, we restricted these analyses to the NFW. We found that, in comparison to faculty at Ph.D.-granting institutions (35\%), a greater percentage of new faculty at non-Ph.D.-granting institutions (67\%) currently use at least one EBIP, and the average number of EBIPs currently used is greater for those at non-Ph.D.-granting institutions (1.9) versus Ph.D.-granting (1.0). This is similar to findings in Henderson and Dancy [28] that faculty use of EBIPs was higher at bachelor's-granting institutions.

We analyzed how many NFW participants have ever tried an EBIP by combining the responses "I have used all or part of it in the past" and "I currently use all or part of it" to the question asking about familiarity with various instructional techniques. We find that $82 \%$ of new faculty have tried at least one EBIP, but that only $66 \%$ of those at $\mathrm{Ph}$.D.-granting institutions have tried any EBIP compared to $95 \%$ of those at primarily undergraduate institutions. Of those who have tried at least one EBIP, more than half report trying more than one, and, on average, new faculty who have tried at least one EBIP report trying four EBIPs. Among experienced faculty, $93 \%$ have tried at least one EBIP.

A year after the workshop, using a matched sample, we found that the percentage of faculty who do not currently use any EBIP had decreased from $31 \%$ to $13 \%$, and the percentage of faculty using each listed EBIP increased (Table V, columns D and E). The average number of EBIPs used also increased for this matched sample, from 2.1 to 3.4. We do not attempt to analyze discontinuation rates since the sample sizes for each EBIP are too small for this purpose.

In comparing to historical data [28], we find similar levels of use for most techniques except for Cooperative Group Problem Solving (Table V, Column A). However, the more recent revisiting study [61] reported higher levels of use.

\section{LIMITATIONS}

Our sample is restricted to those who attended the workshop (fewer than half of new hires), and to those who answered the survey. Because $85 \%$ responded to the preworkshop survey, the conclusions about new faculty before the workshop are less subject to sample bias. Responses are likely subject to response bias such as social desirability (trying to present oneself well; [63]) and effort justification (that it was worth the time to attend the workshop; [64]). We also recognize the limitations of our ability to make causal claims due to the small sample size of the faculty members who responded to the one-year survey; this limitation restricts our analyses to aggregate comparisons rather than individual change. Moreover, we recognize the limitations of our comparison data for contextualization: the sample size of experienced faculty who participated in the EFW is small. The percent of EFW participants reporting the use of any particular EBIP is as little as half that reported in the updated study by Dancy and Henderson [61], suggesting that our EFW participants may be using fewer EBIPs than physics faculty nationally and thus may not be as representative as our NFW sample. To address these limitations, we presented and discussed the comparison data together to help contextualize the results for new faculty rather than focus on characterizing the practices of experienced faculty.

Our survey instruments have several limitations. Some changes in survey wording resulted in a post hoc combination of response codes (see survey instruments). Estimated use of methods is artificially inflated in the one-year survey because of the lack of an "I have never used it" option for two cohorts. We were not able to measure persistence in using EBIPs past one year. We also did not include nonbinary gender options. This is a limitation of our survey design which we will address in future surveys for purposes of inclusion, although we would urge caution in disaggregating data by a third (small) gender option for risk of revealing identifiable information. The few participants who chose "prefer not to answer" were removed from analysis. Lastly, the seven Likert-scale questions we used to determine pre-existing motivation, interest, and confidence in active learning relied on individual questions to measure complex constructs.

We rely on self-report surveys as proxies for actual teaching practice. While earlier studies have indicated a mismatch between self-reports and actual practice [65], several more studies suggest a positive relationship between self-report and practice $[17,22,23,66]$. In the current study, we also find some evidence of consistency across several measures of reported teaching practice (see Sec. II).

Another limitation is that our data rely heavily on measuring faculty members' knowledge and use of a set of specific teaching methods; that is, the list of published curricula and approaches which make up the EBIPs in our study. This reliance is problematic because faculty may interpret terms like "Peer Instruction" too broadly to mean any technique involving peer interaction [11,31]; no description was given of each method in our study. Additionally, measuring EBIPs which are more prevalent or normative in one discipline or another may limit 
transferable findings that can generalize across disciplines. However, the same critique applies equally to our study and the earlier studies [28,31], so our results are likely comparable to this historical data set. Perhaps a more important critique of this approach, however, is that faculty may use active learning without using any of these "official" teaching methods [67]. These factors limit our confidence in the meaningfulness of measures of EBIP use. This concern will be discussed further in Sec. VI.

\section{DISCUSSION}

We report on teaching attitudes, beliefs and practices of a large sample of new faculty so that professional development can better meet the needs of the incoming professoriate. Below, we outline how our results provide evidence to answer our original research questions, within the framework of the ID model (Fig. 1). We generally find evidence that new physics faculty may have progressed through the knowledge stage of the ID model, and most are within the persuasion or decision and implementation stage for one or more techniques. However, there are likely gaps in their knowledge and attitudes which could further support their commitment to student-centered teaching, and their continued development as effective teachers. In this discussion we provide some comparisons to Henderson and Dancy [28], who surveyed physics faculty $(n=722)$ with an average of 15 years of teaching experience, using a similar list of EBIPs to the current study, as well as to an in-progress follow up of that study [61].

\section{A. RQ1: Attitudes and beliefs}

"To what degree do new physics faculty possess attitudes, and beliefs-particularly self-efficacy, value, and perception of support by others-which could support decisions to use student-centered practice?"

We find that new physics faculty (in general) already value student-centered instruction, and feel supported by others, judging by responses to Likert-scale questions about active learning. Gaps remain in new faculty members' self-efficacy to use active learning. Self-efficacy is the confidence in one's ability to successfully undertake a behavior [41]; perceived skill and competence are thus both implicit measures of this confidence. Responses to Likert-scale questions about knowledge, skill, and confidence in using active learning show room for growth. However, only self-reported knowledge is enhanced by the workshop, which is only a small piece of building self-efficacy. That said, the attitude and belief questions may not capture a shift in participants understanding of what encompasses active learning (see Ref. [43] for a discussion of response-shift bias).

Faculty at Ph.D.-granting institutions reported lower confidence in their ability to support colleagues or get good student evaluations, suggesting that self-efficacy may be an important area to further develop for this population.
These faculty also reported greater gains in their beliefs in the effectiveness of active learning as a result of the workshop, suggesting that professional development can still effectively promote increases in the faculty members' understanding of the value of active learning for some groups. These results also suggest that faculty at Ph.D.-granting institutions may need slightly different levels of support, perhaps reflecting the different norms and larger class structures at such institutions.

The relative lack of self-efficacy is of concern given that it is likely a critical link in connecting intention to practice in TPB [37-40]. Additional research is needed to uncover approaches to build faculty members' self-efficacy in professional development settings.

\section{B. RQ2: Knowledge}

"To what degree do new faculty report knowing about student-centered instruction (particularly EBIPs), and how has this changed over the past decade?"

Our investigation of research question 2 focuses on knowledge of active learning and EBIPs as elements of student-centered learning. Faculty reported modest levels of knowledge of active learning (median 3, "some"). Across all studied EBIPs, $80 \%$ of new faculty reported familiarity with at least one EBIP. New faculty have had some exposure to EBIPs as prefaculty (students or TAs); about half reported exposure to at least one EBIP prior to their faculty appointment. Experienced faculty reported much greater levels of knowledge of EBIPs than new faculty; 92\% were familiar with at least one EBIP (compared to $80 \%$ of new faculty) and their knowledge of any single EBIP was higher than that of new faculty (Fig. 4). Physics faculty members' awareness of EBIPs increased with teaching experience, being lowest among prefaculty and highest among experienced faculty, suggesting that their knowledge is developed through professional channels (such as conferences or journals) as they engage in their academic career.

New faculty awareness of any single EBIP in our study was either on par with or slightly lower than the data from Henderson and Dancy [28], where 87\% reported familiarity with at least one EBIP (compared to $80 \%$ in the current study), and 50\% reported familiarity with more than five EBIPs (compared to $15 \%$ in the current study). Faculty awareness in our study was also much lower than those reported in the recent follow-up study [61]; up to $20 \%$ more faculty in the follow-up study reporting knowledge of many EBIPs. These results suggest that our new faculty sample has not yet been exposed to as wide a range of EBIPs as these more experienced populations of physics instructors, perhaps due to their early career stage. The Dancy and Henderson follow-up results [61], showing increased levels of awareness and use of EBIPs, suggest that norms about teaching practices in physics may have shifted since 2007 and that this was not captured in our study. 
Thus, new physics faculty demonstrate awareness of active learning and EBIPs, which could support their decision to use such methods in their teaching-but this awareness shows room for growth, especially when compared to other relevant populations.

\section{RQ3: Teaching practices}

"To what degree do new faculty report using studentcentered teaching practices, and how has this changed over the last decade?"

New faculty report fairly high levels of use of studentcentered teaching practice, based on several different measures used in the study.

Most new faculty have used EBIPs, especially those EBIPs which were well known among the sample. Most new faculty $(82 \%)$ have tried an EBIP currently or in the past, and about half (57\%) currently use one. New physics faculty members' use of any single EBIP was either the same or higher than 10 years ago [28] suggesting increased use of EBIPs over time. Our results for EBIP use among new physics faculty are somewhat lower than other recent reports for mixed-experience samples [61] suggesting that use of such methods is even more widespread among more experienced teaching faculty.

Most new faculty reported using some level of active learning before attending the workshop, and these results are strikingly similar to previous work. We found that $45 \%$ of new faculty use more than $25 \%$ of class time on active learning, whereas Dancy and Henderson [31] reported 44\% of mixed-experience faculty used $30 \%$ or more of class time on active learning. Note, however, that high levels of use of active learning, or using more EBIPs, may not actually be related to increased student learning (see Ref. [68]).

New faculty reported relatively high levels of studentcentered practice (PIPS mean 62.1), though with a broad range (SD 14.0). Those faculty members reporting higher levels of use of student-centered practice also tended to report higher levels of skill in using active learning (item 2), suggesting a connection between practice and self-efficacy. While these data about levels of teaching practice and skill are correlational, we hypothesize that the causality may be bidirectional; greater self-efficacy leads to changes in teaching practice, and greater experience teaching leads to selfefficacy. If the two do build on one another in this way, then encouraging participants to try something new when they return to their home institution may further boost a sense of mastery. A useful future avenue of research would be to investigate the relationship of classroom experimentation and self-efficacy in the months postworkshop.

Our results suggest that most new physics faculty may have already progressed into the implementation stage of the ID model for at least one teaching technique, and thus that they bring directly relevant productive resources and experience to professional development workshopsdespite relatively novice levels of awareness of such techniques. Thus, knowledge does not necessarily predict implementation rates, in keeping with the ID model which requires a persuasion or decision stage prior to implementation.

\section{RQ4: One year later}

"How do these attributes and teaching practices change one year after a professional development experience? (implementation and confirmation)"

A year after the workshop, new physics faculty did not report significant differences in their self-efficacy (Likertscale items on knowledge, skill, or confidence) in using active learning, or in their belief in the effectiveness of these strategies, suggesting little change regarding persuasion or decision. They do teach differently, however. A year after the workshop, self-reported use of student-centered practice has increased compared to preworkshop levels and exceeds that of the experienced faculty sample. Many respondents $(41 \%)$ increased their level of use of active learning, and the percent using high levels of active learning increases from $41 \%$ (preworkshop) to $67 \%$ (one year later), whereas only $45 \%$ of experienced faculty reported high levels of use. New faculty use more EBIPs by one-year postworkshop (increasing from 2.1 preworkshop to 3.4 at one-year), and the percent of new faculty not using any EBIP dropped from $31 \%$ to $13 \%$, a lower nonuse rate than experienced faculty (30\% using no EBIP). Student-centered teaching practices (measured by PIPS) also increased at one year (average score 69.6 compared to 62.1 preworkshop). Few one-year respondents reported using no student-centered practice by any measure: very few $(22 \%)$ reported low levels of active learning at one year, only $13 \%$ use no EBIPs, and 6\% have low studentcentered practice scores $(<50)$ on the PIPS.

Previous work showed that most faculty try a technique for at least one semester, but that approximately $1 / 3$ of faculty abandon a technique over time, with discontinuation rates for any one EBIP of 27\%-80\% [28,31], and that discontinuation is not affected by participation in the NFW [30]. However, the number of one-year respondents using any of the EBIPs exceeds that reported in the 2007 survey [28] by more than a factor of 2 . Thus, new faculty may maintain high levels of use of EBIPs, but this seems overly optimistic in the face of previous studies. Longer-term data collection would allow us to test this hypothesis.

\section{CONCLUSIONS AND IMPLICATIONS}

Across research questions 1-3, our findings may suggest shifting norms of practice in physics. Most new faculty are aware of specific teaching methods (EBIPs), they enter the workshop with a sense that active learning is valuable, and they feel supported by their peers in using active learning. While they have not been exposed to as many EBIPs as more experienced colleagues in this and other studies, 
some have seen these techniques prior to their faculty appointment, and they have dabbled with active learning, student-centered instruction, and EBIPs. We could hypothesize that the evidence base for such practices may be more accepted, and so new faculty do not feel as compelled to seek justification for their use of student-centered practices by seeking out knowledge and literature. Their focus is now on implementation of student-centered instruction, including developing the skills and confidence (i.e., self-efficacy) to do it well. Research question 4 suggests that new faculty are also especially open to experimenting with studentcentered instruction after a professional development workshop, and report very high levels of use one year later, exceeding use by experienced faculty. Thus, most new faculty appear to need minimal encouragement to move through the persuasion or decision phases of the ID model for an instructional technique, and are instead already deep in experimenting (the implementation stage of the ID model). We find the lenses of SDT and TBP to be valuable in considering the factors leading to these instructional choices, and consider that self-efficacy and agency (i.e., "perceived behavioral control" from TBP) are critical considerations for further support of faculty instructional choices.

However, we should be cautious to not overgeneralize that all faculty are interested and engaged in developing their teaching. We consistently find at least $20 \%$ of new faculty whose practices differ from the rest of the sample, judging from our various preworkshop measures: $22 \%$ report spending small portions of class time on active learning, $18 \%$ report knowing no EBIPs, $22 \%$ have low student-centered PIPS scores (below 50), and $43 \%$ report using none of the listed EBIPs. We also see differences by institutional context. Compared to those at non-Ph.D.granting institutions, twice the fraction of faculty at $\mathrm{Ph} . \mathrm{D}$.granting institutions have never used any EBIP (67\% compared to $35 \%$ of faculty), they use about half the number of EBIPs (1 vs 1.9 EBIPs used), and they are less likely to have tried at least one technique $(66 \%$ vs $95 \%$ of faculty). We must use caution in interpreting the EBIP data in particular, since there are many active learning strategies which are not "official" EBIPs [13,68]; however, the consistency of these findings across multiple measures do suggest that there is a subset of about $1 / 5$ of new faculty who have not experimented as much with student-centered instruction.

\section{A. Implications for faculty change theories}

Our findings show that faculty are actively engaged in experimenting with their teaching; they have used various elements of student-centered instruction, but continue to seek new ideas, dropping and adding techniques over time. This is not consistent with a linear model of adoption (Fig. 1). Faculty are likely on different stages of a continuing cycle of teaching improvement, both with

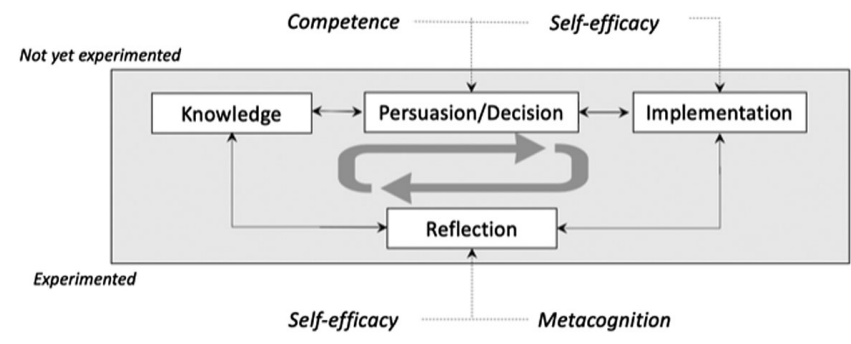

FIG. 5. The innovation-decision model of teaching improvements, reenvisioned to incorporate cyclic improvements and reflection (adapted from Andrews and Lemons [19], Fig. 3) and with some differentiation by experience with active learning (not yet experimented vs experimented).

respect to any single teaching method, and to teaching innovation as a whole. We find it productive to imagine the ID model not as a linear trajectory but as an iterative loop, as suggested by Andrews and Lemons [19], renaming confirmation as reflection, to better reflect teaching change as an iterative, ongoing process (Fig. 5). For any individual teaching method, one could imagine a faculty member engaging in multiple innovation-decision "loops" until that technique is solidified in their teaching and continued iteration is no longer needed. By engaging in ID loops for a variety of practices, the faculty member will (over their career) develop a suite of tools for a fully interactive classroom, practical strategies and skills, and a habit of reflective teaching and knowledge seeking [22,32,33]. Different types of faculty may progress differently through this cycle $[10,67]$.

\section{B. Implications for promoting specific EBIPs in faculty development settings}

It may not be appropriate to aim for the adoption of branded EBIPs as the goal of professional development (the "teaching-method-centered paradigm"; [68]). Physics education research (among others) has historically included a focus on developing adoptable curricula and methods (branded EBIPs; [13]), disseminating them to faculty, and supporting faculty in using these methods with fidelity $[29,69]$. We are concerned that such a focus implicitly propagates a deficit model of faculty as learners [68,70]. The current design of the NFW likely reflects this history; previous work on the NFW suggested that the workshop was often overly prescriptive and authoritarian in teaching faculty about these methods, leaving "little space for faculty to grapple with their incoming ideas about teaching and learning" [35,71]. However, the NFW has evolved since that publication, guided in part by that feedback. Our findings suggest room for growth in faculty's self-efficacy, and further research may uncover new ways to support faculty as autonomous decision-makers who reflect on their teaching and draw on multiple productive resources in a process of continuing development [68,72]. While the 
ultimate aim is for this development to include studentcentered instruction, such instruction may or may not encompass any branded EBIPs.

\section{Implications for professional development}

Our results suggest that the role of professional development for most faculty is not in a persuasive one, but rather to support them as active agents who are progressing through new "loops" of the ID process for one or more instructional methods. To best support continued and productive progression through these ID loops, faculty need to consider their current goals and gaps in their instruction. Professional development should thus strengthen metacognition and reflection [72] and provide conceptual frameworks about teaching to provide the foundation for future learning [68], including pedagogical sensemaking and the "pursuit of robust pedagogical logic based on observations and interpretations of classroom events" [35]. Thus, productive outcomes for professional development may include competence, self-efficacy, and metacognition (Fig. 5). Achieving such outcomes may launch faculty on a new round of the ID cycle. It is also important to ensure that faculty see value in studentcentered instruction (Fig. 1), but this may be less critical given results from our study and changes in perception on a national scale [3]. See Strubbe et al. [68] for a thoughtful exploration of how these desired outcomes align with a focus on faculty agency around teaching.

Given these desired outcomes, it may be appropriate for professional developers to provide gentle, respectful introductions to teaching techniques which assume some level of knowledge and interest, albeit with some misperceptions. One might also focus on the workshop as a "gateway" experience $[30,46]$, where the aim is to get faculty to try something new and learn from that experience [73]. A willingness to try something and learn from it is a part of meaningful reflection [19,74], and those who have not used a new technique tend to have fears about the technique which do not match the actual challenges [11]. A focus on productive classroom experimentation may improve faculty members' perceived skill in using active learning along with their knowledge of techniques.

Professional developers also need to be mindful of the diversity of new faculty, given the $\sim 20 \%$ of new faculty who do not feel as knowledgeable or motivated, and have not experimented as much with their teaching. These faculty (many of whom are at Ph.D.-granting institutions) may not yet be at the implementation stage, and they may need slightly different interventions (such as gentle persuasion and building competence) to support them through their first round of the cycle, with agency being critical for supporting their initial experiments (see Fig. 5).

\section{Implications for research}

In future research, we also suggest moving away from a research and evaluation framework in which faculty knowledge and use of specific EBIPs are measured. While this was our approach in the current paper, we now find this to be a flawed approach. It would be valuable to disentangle the attitudinal attributes we perceive as related to agency and self-efficacy (e.g., skill, confidence, autonomy, identity) and to develop valid and reliable measures of these attitudes. Further interpretive studies of the PIPS would be similarly useful. Using our proposed model of teaching change (Fig. 5), especially in light of different experiences and backgrounds of diverse faculty, would be informative for the field. While the current study is in physics, the messages are likely to be relevant to other fields. Additional studies can help to better understand how teacher knowledge, beliefs, and attitudes contribute to effective and sustained use of student-centered instruction and how these may differ by discipline, which will make further progress in changing STEM instruction.

\section{ACKNOWLEDGMENTS}

Special thanks to Charles Hayward, Marilyne Stains, Charles Henderson, and Alice Olmstead, who contributed to the original survey design. Thanks to the NFW team (Robert Hilborn, Ed Prather, Ted Hodapp, and Andy Rundquist) for their engagement and interpretation of findings. A debt of gratitude is extended to Eleanor Sayre with whom author S. V.C. refined the focus on faculty agency and the iterative, cyclic innovation-decision cycle. This work is supported by NSF DUE under Grant No. 1431638 and Chasteen Educational Consulting. The authors form the external evaluation team for the NFW and have conducted data collection and analysis as consultants in that role. Authoring of the paper itself was not included as this consulting agreement. 
[1] S. Freeman, S. L. Eddy, M. McDonough, M. K. Smith, N. Okoroafor, H. Jordt, and M. P. Wenderoth, Active learning increases student performance in science, engineering, and mathematics, Proc. Natl. Acad. Sci. U.S.A. 111, 8410 (2014).

[2] M. K. Eagan, E. B. Stolzenberg, J. Berdan Lozano, M. C. Aragon, M. R. Suchard, and S. Hurtado, Undergraduate Teaching Faculty: The 2013-2014 HERI Faculty Survey (Higher Education Research Institute, UCLA, Los Angeles, 2014).

[3] S. Laursen, T. Andrews, M. Stains, C. Finelli, M. Borrego, D. McConnell, E. Johnson, and K. Foote, Levers for Change: An Assessment of Progress on Changing STEM Instruction (American Association for the Advancement of Science, Washington, DC, 2019), https://www.aaas.org/ resources/levers-change-assessment-progress-changingstem-instruction.

[4] M. Stains, J. Harshman, M. K. Barker, S. V. Chasteen, R. Cole, S. E. DeChenne-Peters, and A. M. Young, Anatomy of STEM teaching in North American universities, Science 359, 1468 (2018).

[5] The Role of Scientific Societies in STEM Faculty Workshops, edited by R. C. Hilborn (American Association of Physics Teachers College Park, MD, 2013).

[6] National Research Council, Discipline-Based Education Research: Understanding and Improving Learning in Undergraduate Science and Engineering (National Academies PressWashington, DC, 2012).

[7] K. Viskupic, K. Ryker, R. Teasdale, C. Manduca, E. Iverson, D. Farthing, M. Z. Bruckner, and R. McFadden, Classroom observations indicate the positive impacts of discipline-based professional development, J. STEM Educ. Res. 2, 201 (2019).

[8] C. Henderson, R. Cole, J. E. Froyd, D. G. Friedrichsen, R. Khatri, and C. Stanford, Designing Educational Innovations for Sustained Adoption: A How-To Guide for Education Developers Who Want to Increase the Impact of Their Work (Increase the Impact, Kalamazoo, MI, 2015).

[9] E. R. Landrum, K. Viskupic, S. E. Shadle, and D. Bullock, Assessing the STEM landscape: The current instructional climate survey and the evidence-based instructional practices adoption scale, Int. J. STEM Educ. 4, 1 (2017).

[10] A. Madsen, S. B. McKagan, E. C. Sayre, M. S. Martinuk, and A. Bell, Personas as a powerful methodology to design targeted professional development resources, in Learning and Becoming in Practice, Proceedings of the International Conference of the Learning Sciences, Boulder, $C O$ (The International Society of the Learning Sciences, 2014), pp. 1082-1086, https://arxiv.org/abs/1408 .1125 .

[11] C. Turpen, M. Dancy, and C. Henderson, Perceived affordances and constraints regarding instructors' use of Peer Instruction: Implications for promoting instructional change, Phys. Rev. Phys. Educ. Res. 12, 010116 (2016).

[12] S. A. Ambrose, M. W. Bridges, M. DiPetro, M. C. Lovett, and M. K. Norman, How Learning Works: Seven Research-Based Principles for Smart Teaching (Jossey-Bass San Francisco, CA, 2016).

[13] R. Khatri, C. Henderson, R. Cole, J. E. Froyd, D. Friedrichsen, and C. Stanford, Characteristics of well- propagated teaching innovations in undergraduate STEM, Int. J. STEM Educ. 4, 1 (2017).

[14] S. E. Brownell and K. D. Tanner, Barriers to faculty pedagogical change: lack of training, time, incentives, and ... tensions with professional identity?, CBE Life Sci. Educ. 11, 339 (2012).

[15] D. K. Cohen and J. D. Mehta, Why reform sometimes succeeds: Understanding the conditions that produce reforms that last, Am. Educ. Res. J. 54, 644 (2017).

[16] C. Henderson, A. Beach, and N. Finkelstein, Facilitating change in undergraduate STEM instructional practices: an analytic review of the literature, J. Res. Sci. Teach. 48, 952 (2011).

[17] T. Lund and M. Stains, The importance of context: An exploration of factors influencing the adoption of studentcentered teaching among chemistry, biology, and physics faculty, Int. J. STEM Educ. 2, 1 (2015).

[18] S. E. Shadle, A. Marker, and B. Earl, Faculty drivers and barriers: laying the groundwork for undergraduate STEM education reform from academic departments, Int. J. STEM Educ. 4, 1 (2017).

[19] T. C. Andrews and P. P. Lemons, It's personal: Biology instructors prioritize personal evidence over empirical evidence in teaching decisions, CBE Life Sci. Educ. 14, 1 (2015).

[20] J. Bouwma-Gearhart, Research university STEM faculty members' motivation to engage in teaching professional development: building the choir through an appeal to extrinsic motivation and ego, J. Sci. Educ. Technol. 21, 558 (2012).

[21] J. Gess-Newsome, S. Southerland, A. Johnston, and S. Woodbury, Educational reform, personal practical theories, and dissatisfaction: The anatomy of change in college science teaching, Am. Educ. Res. J. 40, 731 (2003).

[22] C. A. Manduca, E. R. Iverson, M. Luxenberg, R. H. Macdonald, D. A. McConnell, D. W. Mogk, and B. J. Tewksbury, Improving undergraduate STEM education: the efficacy of discipline-based professional development, Sci. Adv. 3, e1600193 (2017).

[23] R. Teasdale, K. Viskupic, J. K. Bartley, D. McConnell, C. Manduca, M. Bruckner, D. Farthing, and E. Iverson, A multidimensional assessment of reformed teaching practice in geoscience classrooms, Geosphere 13, 608 (2017).

[24] C. Henderson and M. Dancy, Barriers to the use of research-based instructional strategies: The influence of both individual and situational characteristics, Phys. Rev. Phys. Educ. Res. 3, 020102 (2007).

[25] J. M. Bailey and K. Nagamine, Experiencing conceptual change about teaching: A case study from astronomy, Am. J. Phys. 80, 542 (2012).

[26] R. H. Stupinsky, A. BrckaLorenz, B. Yuhas, and F. Guay, Faculty members' motivation for teaching and best practices: Testing a model based on self-determination theory across institution types, Contemp. Educ. Psychol. 53, 15 (2018).

[27] E. Rogers, Diffusion of Innovations (Free Press New York, 2003).

[28] C. Henderson and M. H. Dancy, Impact of physics education research on the teaching of introductory quantitative physics in the United States, Phys. Rev. Phys. Educ. Res. 5, 020107 (2009). 
[29] C. Henderson and M. Dancy, Physics faculty and educational researchers: Divergent expectations as barriers to the diffusion of innovations, Am. J. Phys. 76, 79 (2008).

[30] C.Henderson, M. Dancy, and M. Niewiadomska-Bugaj, Use of research-based instructional strategies in introductory physics: Where do faculty leave the innovation-decision process?, Phys. Rev. Phys. Educ. Res. 8, 020104 (2012).

[31] M. Dancy and C. Henderson, Pedagogical practices and instructional change of physics faculty. Am. J. Phys. 78, 1056 (2010).

[32] M. Devlin, Challenging accepted wisdom about the place of conceptions of teaching in university teaching improvement, Int. J. Teach. Learn. Higher Educ. 18, 112 (2006).

[33] G. Gibbs and M. Coffey, The impact of training of university teachers on their teaching skills, their approach to teaching and the approach to learning of their students, Active Learning Higher Educ. 5, 87 (2004).

[34] R. E. Gibbons, S. M. Villafane, M. Stains, K. L. Murphy, and J. R. Raker, Beliefs about learning and enacted instructional practices: An investigation in postsecondary chemistry instruction, J. Res. Sci. Teach. 55, 1111 (2018).

[35] A. Olmstead and C. Turpen, Pedagogical sensemaking or "doing school": In well-designed workshop sessions, facilitation makes the difference, Phys. Rev. Phys. Educ. Res. 13, 020123 (2017).

[36] E. L. Deci and R. M. Ryan, Self-determination theory in Handbook of Theories of Social Psychology, edited by P. A. M. Van Lange, A. W. Kruglanski, and E. T. Higgins (Sage Publications, Thousand Oaks, CA, 2012), Vol. 1, pp. 416-437.

[37] I. Ajzen, The theory of planned behavior: Reactions and reflections, Psychol. Health 26, 1113 (1991).

[38] M. Fishbein and I. Azien, Predicting and Changing Behavior: The Reasoned Action Approach (Taylor \& Francis New York, NY, 2010).

[39] N. Jacobs, M. S. Hagger, S. Streukens, I. De Bourdeaudhuij, and N. Claes, Testing an integrated model of the theory of planned behaviour and self-determination theory for different energy balance-related behaviours and intervention intensities, Brit. J. Health Psychol. 16, 113 (2011).

[40] M. S. Hagger, N. L. D. Chatzisarantis, and J. Harris, The process by which relative autonomous motivation affects intentional behavior: Comparing effects across dieting and exercise behaviors, Motiv. Emotion 30, 307 (2006).

[41] A. Bandura, Self-Efficacy: The Exercise of Control (W.H. Freeman, New York, NY, 1997).

[42] S. Chasteen and R. Chattergoon, Supporting teaching autonomy in the New Faculty Workshop, in Proceedings of the 2018 American Association of Physics Teachers Conference, Washington, DC (2018). Retrieved from https://www.chasteenconsulting.com/wp-content/uploads/ 2019/07/NFW-AAPT-2018-poster-v2.pdf.

[43] S. V. Chasteen and R. Chattergoon, Measuring faculty attitude change toward active learning within the New Faculty Workshop for Physics and Astronomy, in Proceedings of the 2019 Physics Education Research Conference, Provo, UT (AIP, New York, 2019).

[44] S. Chasteen, R. Chattergoon, E. Prather, and R. Hilborn, Evaluation methodology and results for the New Faculty Workshops, in Proceedings of the 2016 Physics Education
Research Conference, Sacramento, CA (AIP, New York, 2016).

[45] American Institute of Physics, Physics Trends: Number of Faculty Hired by Physics (AIP, New York, 2017). Retrieved from https://www.aip.org/statistics/physics-trends/ number-faculty-hired-physics-departments.

[46] C. Henderson, Promoting instructional change in new faculty: An evaluation of the Physics and Astronomy New Faculty Workshop, Am. J. Phys. 76, 179 (2008).

[47] A. Rundquist, J. Corbo, S. Chasteen, M. Martinuk, C. Henderson, and M. Dancy, Faculty online learning communities to support physics teaching, in Proceedings of the 2015 Physics Education Research Conference, College Park, MD (AIP, New York, 2015).

[48] A. M. Porter and R. Ivie, AIP Report: Women in Physics and Astronomy (AIP, New York, 2019). Retrieved from https://www.aip.org/sites/default/files/statistics/women/ Women \%20in\%20Physics\%20and\%20Astronomy\% 202019.1.pdf.

[49] R. Ivie, G. Anderson, and S. White, AIP Focus on: African Americans \& Hispanics among Physics \& Astronomy Faculty: Results from the 2012 Survey of Physics \& Astronomy Degree-Granting Departments (AIP, New York, 2014). Retrieved from https://www.aip.org/sites/default/ files/statistics/faculty/africanhisp-fac-pa-123.pdf.

[50] American Institute of Physics, Physics Trends: Total FullTime Equivalent (FTE) Faculty Members in Physics Departments by Highest Degree Awarded, 2012 to 2018 (AIP, New York, 2018). Retrieved from https://www.aip .org/statistics/data-graphics/total-full-time-equivalent-ftefaculty-members-physics-departments- 0 .

[51] See Supplemental Material at http://link.aps.org/ supplemental/10.1103/PhysRevPhysEducRes.16.020164 for copies of the most recent (November 2017) versions of the preworkshop, postworkshop, and one-year survey.

[52] J. M. Allen and K. Nimon, Retrospective pre-test: A practical technique for professional development evaluation, J. Industrial Teacher Educ. 44, 27 (2007), https://eric .ed.gov/?id=EJ830483.

[53] C. N. Hayward, M. Kogan, and S. L. Laursen, Facilitating instructor adoption of inquiry-based learning in college mathematics, Int. J. Res. Undergrad. Math. Educ. 2, 59 (2016).

[54] L. R. Prieto and E. M. Altmaier, The relationship of prior training and previous teaching experience to self-efficacy among graduate teaching assistants, Res. High. Educ. 35, 481 (1994).

[55] M. Stains, M. Pilarz, and D. Chakraverty, Short and longterm impacts of the Cottrell Scholars collaborative new faculty workshop, J. Chem. Educ. 92, 1466 (2015).

[56] E. M. Walter, C. R. Henderson, A. L. Beach, and C. T. Williams, Introducing the Postsecondary Instructional Practices Survey (PIPS): A concise, interdisciplinary, and easy-to-score survey, CBE Life Sci. Educ. 15, ar53 (2016).

[57] E. Mazur, Peer Instruction, A User's Manual (PrenticeHall Upper Saddle River, NJ, 1997).

[58] D. R. Sokoloff and R. K. Thornton, Using interactive lecture demonstrations to create an active learning environment, Phys. Teach. 35, 340 (1997). 
[59] W. K. Adams, S. Reid, R. LeMaster, S. B. McKagan, K. K. Perkins, M. Dubson, and C. E. Wieman, A study of educational simulations part I-engagement and learning, J. Interact. Learn. Res. 19, 397 (2008), https://www .learntechlib.org/noaccess/24230/.

[60] W. K. Adams and C. E. Wieman, Development and validation of instruments to measure learning of expertlike thinking, Int. J. Sci. Educ. 33, 1289 (2010).

[61] M. Dancy, N. Apkarian, C. Henderson, E. Johnson, J. Raker, and M. Stains, Survey of physics, mathematics and chemistry faculty, Proceedings of the 2019 Physics Education Research Conference, Provo, UT (AIP, New York, 2019). Retrieved from https://sites.google.com/view/ rbisproject/.

[62] P. Heller, R. Keith, and S. Anderson, Teaching problem solving through cooperative grouping. Part 1: Group versus individual problem solving, Am. J. Phys. 60, 627 (1992).

[63] D. L. Paulhus, Socially desirable responding: The evolution of a construct, in The Role of Constructs in Psychological and Educational Measurement, edited by H. I. Braun and D. N. Jackson (Lawrence Erlbaum, Mahwah, NJ, 2002), pp. 49-69.

[64] L. Festinger, Cognitive Dissonance (Stanford University Press, Stanford, CA, 1957).

[65] D. Ebert-May, T. L. Derting, J. Hodder, J. L. Momsen, T. M. Long, and S. E. Jardeleza, What we say is not what we do: Effective evaluation of faculty professional development programs, BioScience 61, 550 (2011).

[66] M. K. Smith, E. L. Vinson, J. A. Smith, J. D. Lewin, and M. R. Stetzer, A campus-wide study of STEM courses:
New perspectives on teaching practices and perceptions, CBE Life Sci. Educ. 13, 624 (2014).

[67] A. Madsen and S. McKagan, User-centered personas for PhysPort, in Proceedings of the 2019 Physics Education Research Conference, Provo, UT (AIP, New York, 2019).

[68] L. E. Strubbe, A. M. Madsen, S. B. McKagan, and E. C. Sayre, Beyond teaching methods: Highlighting physics faculty's strengths and agency, Phys. Rev. Phys. Educ. Res. 16, 020105 (2020).

[69] M. Stains and T. Vickery, Fidelity of implementation: An overlooked yet critical construct to establish effectiveness of evidence-based teaching practice, CBE Life Sci. Educ. 16, rm1 (2017).

[70] M. T. Owens et al., Collectively improving our teaching: Attempting biology department-wide professional development in scientific teaching, CBE Life Sci. Educ. 17, ar2 (2018).

[71] A. Olmstead and C. Turpen, Assessing the interactivity and prescriptiveness of faculty professional development workshops: The real-time professional development observation tool, Phys. Rev. Phys. Educ. Res. 12, 020136 (2016).

[72] C. A. Manduca, Surveying the landscape of professional development research: Suggestions for new perspectives in design and research, J. Geosci. Educ. 65, 416 (2017).

[73] C. D. Czajka and D. McConnell, The adoption of studentcentered teaching materials as a professional development experience for college faculty, Int. J. Sci. Educ. 41, 693 (2019).

[74] L. McAlpine and C. Weston, Reflection: Issues related to improving professors' teaching and students' learning. Instr. Sci. 28, 363 (2000). 